\title{
Campus Teaching Awards, Academic Year 2014-15
}

PSA is pleased to recognize the recipients of campus-wide and departmental awards for teaching excellence during the 2014-15 academic year. Pi Sigma Alpha hosted these recipients at the Reception Honoring Teaching at the APSA Annual Meeting in San Francisco, California. (Photos appear above recipeint's name and institution)

Karen Ruth Adams, University of Montana, Tom Boone Town \& Gown Award

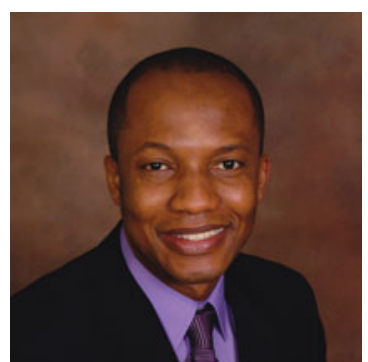

RichardAidoo, Coastal Carolina University, Edwards College of Humanities and Fine Arts Distinguished Teacher Award

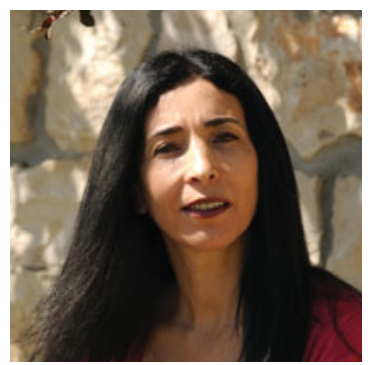

Osnat Akirav, Western Galilee College, Excellence in Teaching

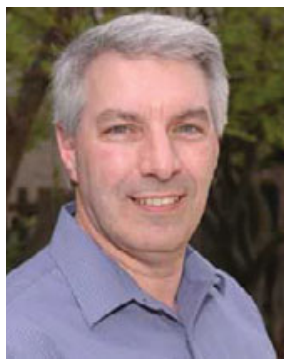

Vincent Auger, Western Illinois University, Provost's Award for Excellence in Teaching

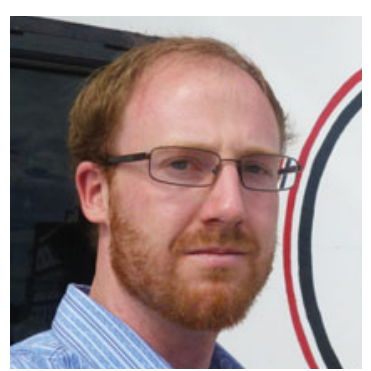

Shane Barter, Soka University of America, Professor of the Year

Sheri Breen, University of Minnesota, Morris, 2014 Alumni Association Teaching Award

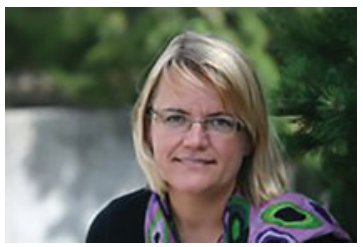

Dovile Budryte, Georgia Gwinnett College, Outstanding Teaching Award

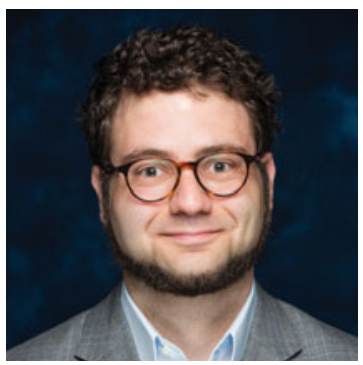

Christopher DeSante, Indiana University Bloomington, Trustees Teaching Award

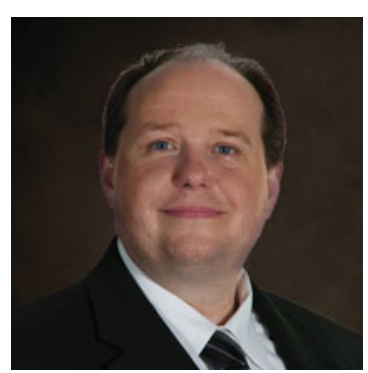

Martin Edwards, Seton Hall University, University Teacher of the Year

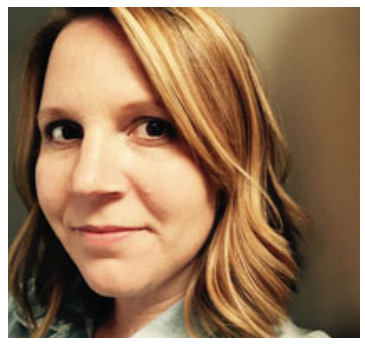

Jessica Feezell, University of New Mexico, UNM Teaching Fellow

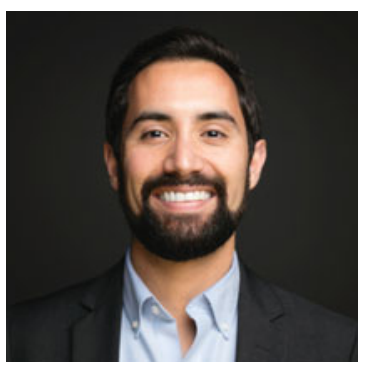

Bernard Fraga, Indiana University Bloomington, Trustees Teaching Award 


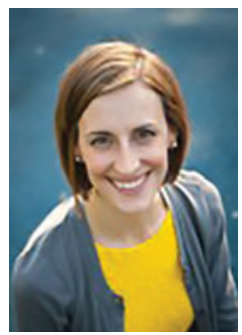

Rebecca Glazier, University of Arkansas at Little Rock, College of Social Sciences and Communication Faculty Excellence Award for Teaching

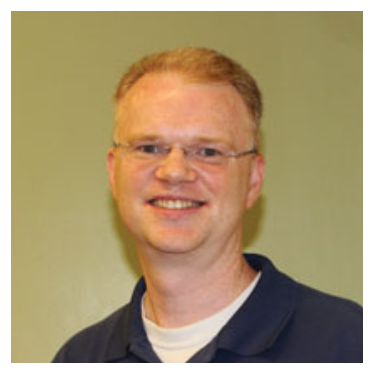

Mark Haas, Duquesne University, McAnulty College Award for Excellence in Teaching

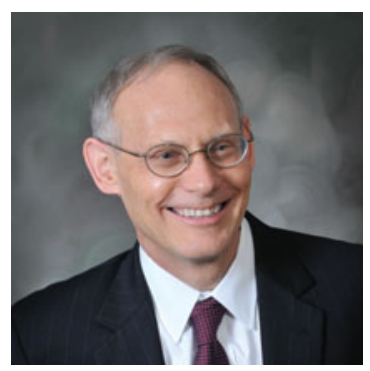

Allen D. Hertzke, University of Oklahoma, Presidential Teaching Fellow

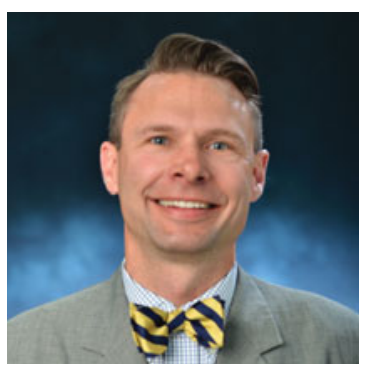

Roudy Hildreth, Southern Illinois University Carbondale, 2014 Universitylevel Teaching Excellence Award

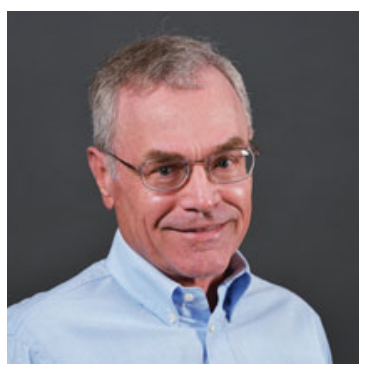

Karl Hokenmaier, Western Michigan University, College of Arts and Sciences Part-time Instructor Excellence in Teaching Award

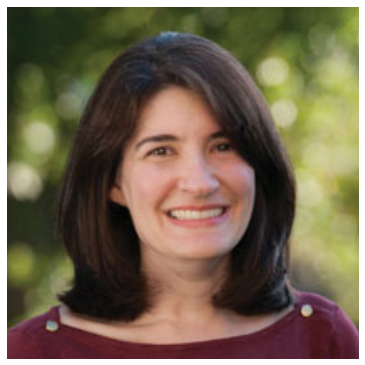

Alison Howard, Dominican University of California, Campus-wide Teacher of the Year

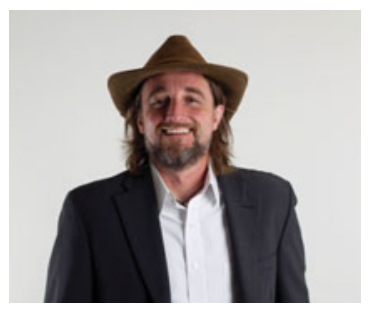

Peter Jacques, University of Central Florida, 2015 University Excellence in Undergraduate Faculty Academic Advising Award, 2015 College of Sciences Teaching Incentive Program (TIP) Award

Anna Kirkland, University of Michigan, Arthur F. Thurnau Professorship at Michigan

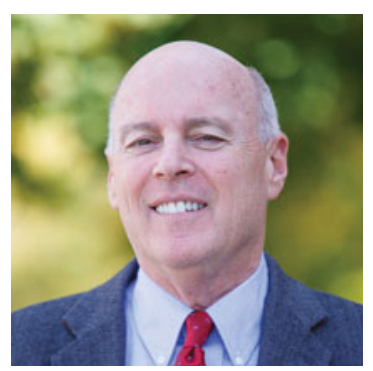

Paul Landow, University of Nebraska at Omaha, Alumni Outstanding Teaching Award

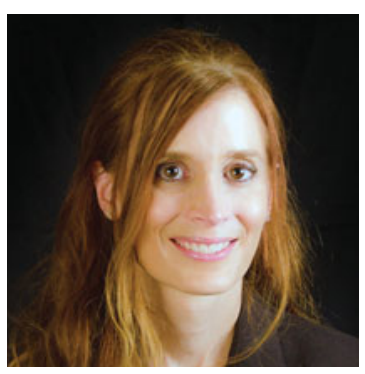

Julie Lantrip, Tarrant County College, Chancellor's Exemplary Teaching Award

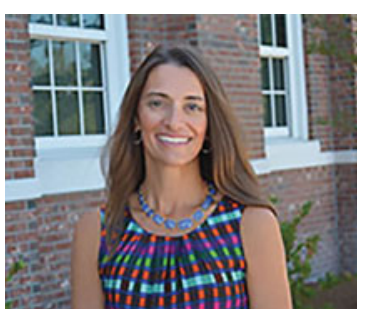

Pamela Martin, Coastal Carolina University, HTC Distinguished Teacher-Scholar

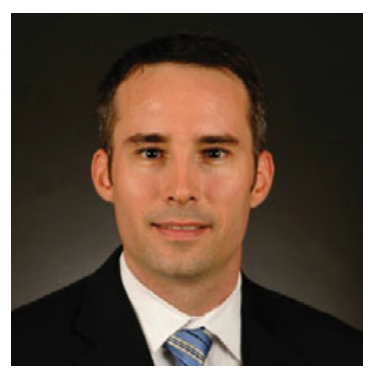

Gregory McBrayer, Morehead State University, Student Government Association, Faculty Member of the Year

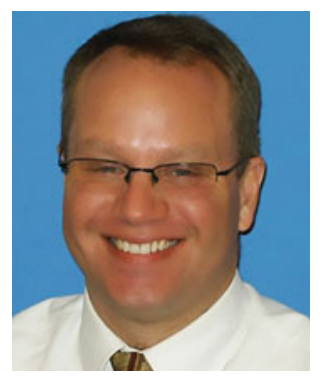

Patick McKinlay, Morningside College, The Sharon Walker Faculty Excellence Award 


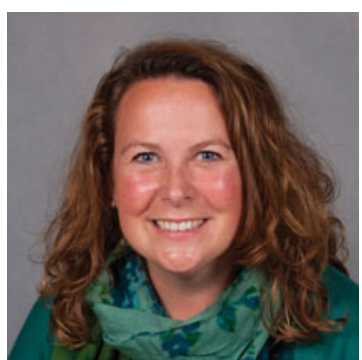

Tricia Mulligan, Iona College, Br. Richard Power Award for Integrating Service Learning into the Classroom

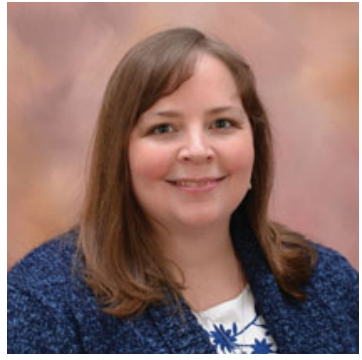

Elizabeth Norell, University of Tennessee at Chattanooga, SGA Outstanding Professor

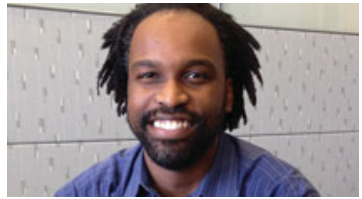

Tatishe Nteta, University of Massachusetts, Amherst, Pi Sigma Alpha Award for Best Professor

Martha Phelps, Alderson Broaddus University, Honorary Coach For Academics (Wrestling)

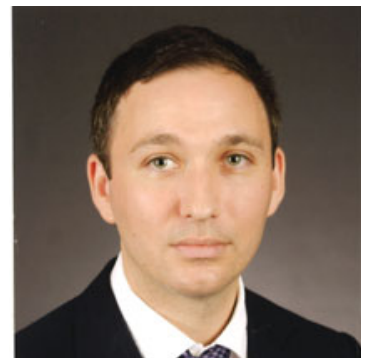

Jonathan Pidluzny, Morehead State University, Dean's Citation for Teaching Excellence and Student Government Association Outstanding Professor/ Faculty Member of the Month

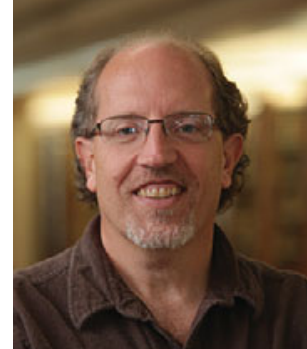

Daniel Ponder, Drury University, Faculty Award for Teaching

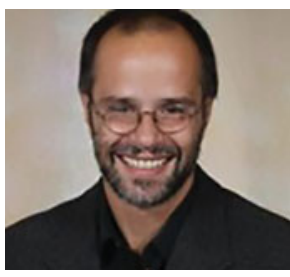

David Romano, Missouri State University, 2015 Missouri State University Foundation Award for Teaching

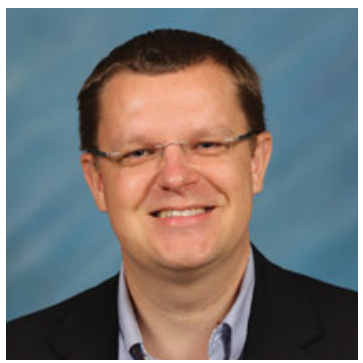

Henrik Schatzinger, Ripon College, May Bumby Severy Award for Excellence in Teaching

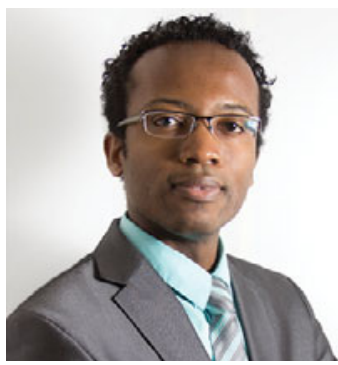

Landry Signé, University of Alaska Anchorage, 2014 Chancellor's Awards for Excellence

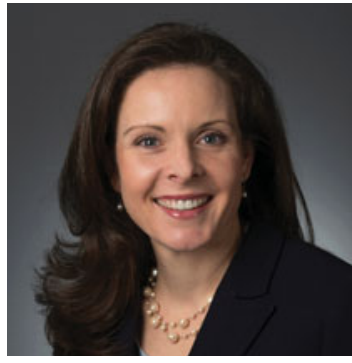

Jennifer Victor, George Mason University, School of Policy, Government, and International Affairs Teaching Award

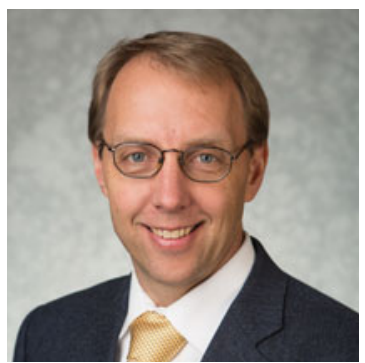

Darren Walhof, Grand Valley State University, University Outstanding Teacher Award

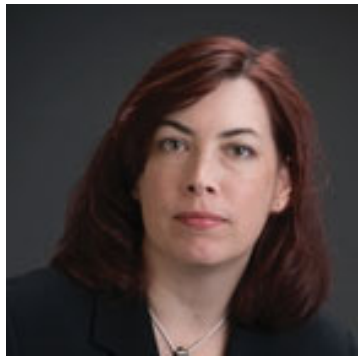

Catherine Warrick, Villanova University, Tolle Lege Teaching Award

Wendy Watson, University of North Texas, 2015 J. H. Shelton Excellence in Teaching Award

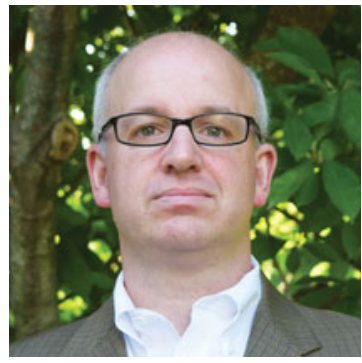

David Yalof, University of Connecticut, 2014 UCONN Alumni Association Faculty Excellence in Undergraduate Teaching Award 


\section{MENA Workshop on "Civil Society in Comparative Perspective"}

APSA is pleased to announce that the 2016 MENA Workshops program, entitled "Civil Society Revisited: Research Associational Life in Comparative Perspective," will be hosted by the American University of Beirut (AUB) and the American University in Cairo (AUC). This two-part workshop program is a unique opportunity to network with colleagues from across the MENA region and develop current research related to civil society in the Arab region and the changing state-society dynamics engendered by the Arab Uprisings of 2011. With support from the Carnegie Corporation of New York, the organizers will cover all costs of participation (including travel, lodging, meals, and materials) for up to 22 qualified applicants. A call for participant applications is forthcoming. Check the MENA Workshops website (www.apsanet.org/menaworkshops) for the latest updates on 2016 programming and beyond.

\section{Bryce Fund to Support International Scholarship}

APSA's Centennial Center for Political Science \& Public Affairs is now accepting applications for supplemental research awards. Established to support the global study of political life and the internationalization of the political science discipline, the James Bryce Fund provides supplemental support for research residencies in the Centennial Center and elsewhere, collaborative research workshops involving political scientists from the United States and abroad, and teaching and curriculum development programs for emerging political science communities. For more information visit: http://www.apsanet.org/centennialcenter.

\section{TIM Membership}

APSA's Targeted International Membership (TIM) is available to scholars in low-income and lower-middle income countries. At a significantly reduced annual dues rate, benefits of TIM include complete access to APSA online services; discounted publications; eJOBS service; subscription to the electronic or hard copy versions of PS: Political Science \& Politics, Perspectives on Politics, and the American Political Science Review. For more information contact: membership@apsanet.org.

1527 NEW HAMPSHIRE AVE., NW, WASHINGTON D.C. 20036-1206 • www.apsanet.org

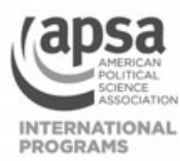

\section{APSA Minority Student Recruitment Program (MSRP)} Become a 2015-2016 APSA MSRP Recruiting Department

The APSA Minority Student Recruitment Program (MSRP) advances the benefits of diversity within the political science profession. The program connects undergraduate students from under-represented backgrounds interested in graduate study with MSRP recruiting departments.

\section{MSRP Departmental Benefits}

- A link to your PhD program on the APSA website and sent to MSRP students

- Access to the MSRP database to recruit undergraduates to your PhD program

- Participation in the MSRP Best Practices meeting

- Access to the MSRP Recruiting Departments listserv

\section{Enroll Students in the MSRP Database}

Faculty are also invited to submit student names and contact information to the Minority Student Recruitment database. Or students may enroll themselves or ask their undergraduate advisor to sponsor them.

Contact diversityprograms@apsanet.org for more information. 